\title{
Effect of water scarcity on groundwater use efficiency in the rice sector of Karnataka: a case study
}

\author{
S. Korattukudy Varghese, P. Chellattan Veettil, J. Buysse, \\ S. Speelman, A. Frija \& G. Van Huylenbroeck \\ Department of Agricultural Economics, Gent University, Belgium
}

\begin{abstract}
Scarcity of a resource is proven to cause prudent and efficient use in many cases. This is contradicted in other studies where common property resource is shown as heavily abstracted in the face of scarcity. Our paper provides a field level examination of the ground water scarcity-use efficiency nexus using causal inference theory. We use data from villages of Madhugiri, Karnataka where groundwater is increasingly becoming a scarce resource. Groundwater Use Efficiency (GWUE) scores are calculated using the concept of sub-vector efficiency in Data Envelopment Analysis. The inefficiencies are then traced to the farm level scarcity indicators using Inverse Probability Weighting method. We use farm level proxies as scarcity indicators such as the age of irrigation! wells, irrigation investment cost and number of wells at farm level. Our study finds that water scarcity affects the GWUE negatively when conditioned on other confounders pointing to higher abstraction behavior in the face of scarcity. This result indicates that maintaining water availability levels at farm level would help in improving GWUE scores.
\end{abstract}

Keywords: scarcity, groundwater use efficiency, South India, rice farming.

\section{Introduction}

In the context of the increasing global water supply-demand mismatch, stakeholders and policy makers are increasingly interested in improving the efficiency of every drop of groundwater extracted and used. Considering the consumptive nature of agricultural water use and the sheer volume of groundwater used for agriculture, it is imperative that Groundwater Use 
Efficiencies (GWUE) be assessed and causal nodes of inefficiencies are identified. With agriculture being the largest consumer of water in many countries [1] and groundwater being the major water supplier for irrigation, policy designers in most of the countries are forced to adopt new policy mechanisms to improve the GWUE.

Economic literature differs in its views concerning the effects of resource scarcity on efficiency. While it is often believed that in abundance, resource use will be inefficient and that scarcity of a resource will cause more prudent use [28], several authors [9-11] report the occurrence of appropriative competition under resource scarcity, implying less efficient use under scarcity. In the light of the inconclusive evidence in the literature, the current paper attempts to estimate, using causal inference theories, the nexus between water scarcity and efficiency of groundwater use in the intensive rice farming system in the central dry zone of Karnataka of India, where groundwater is a critical and a fast depleting resource. We address following questions: (i) Is there a causal effect of water scarcity on the GWUE of farms and (ii) How do intensive rice farmers differ from single rice farmers with regard to GWUE? In contrast with extant empirical analyses of the nexus between water scarcity at individual level and water pumping in the case of groundwater, which have largely been based on experimental settings, this paper uses farm data. An accurate causal estimation of the effect of water scarcity on GWUE at individual farm level, could also lay the foundation to predict the impact on GWUE of policies aiming at modulating the water availability.

\section{Methodology}

\subsection{Study area and cropping system}

Karnataka is one of the most water scarce states of India, where surface water is not available in all villages and an increasing pressure is felt on groundwater abstraction. The study is conducted in Madhugiri taluk of Tumkur which is located in the central dry zone of Karnataka and is currently classified as "overexploited" by the Central Groundwater Board of India (2008). There are two cultivation seasons for rice in this region: the monsoon or kharif season and the dry or rabi season. Intensive rice farming is practiced using irrigation water which in the kharif season supplements the monsoon rain and during the rabi season is the sole water source. Water availability is higher in the kharif season because of the monsoon and the availability of tank water. In the rabi season, the bore-wells cater as the main water supply structures, which in a few occasions are supplemented by dug-wells and tanks. The private ownership of groundwater (wells) in the absence of a legal check on the groundwater extraction causes individual farm structures and characteristics to play a more significant role in the efficiency of groundwater use. 


\subsection{The use of DEA to measure GWUE}

The crux of efficiency analysis is to construct a frontier based on the best performing farms from the data set and to compare the other farms with respect to these best farms in terms of input use or output produced [12-14]. The best practice frontier constructed in nonparametric DEA is a piece-wise linear frontier enveloping the given input or output data [14]. In DEA all the deviations from the frontier (constructed by mathematical programming) are considered as inefficiencies. The firms on the efficiency frontier will have an efficiency score equal to 1 . The inefficiencies of other farms are measured in relation to these farms, and thus in relation to their distance from the frontier. Consider the case of $\mathrm{K}$ farms $(\mathrm{k}=1, \ldots, \mathrm{K})$ using $\mathrm{N}$ inputs $x_{n k}(\mathrm{n}=1, \ldots, \mathrm{N})$ for producing $\mathrm{M}$ outputs $y_{n k}$ $(\mathrm{m}=1, \ldots, \mathrm{M})$. The following linear program (1) represents then the standard VRS DEA model and needs to be resolved $K$ times, each farm once becomes the reference unit.

$$
\begin{gathered}
\operatorname{Min}_{\theta, \lambda} \theta \\
\text { s.t. } \sum_{k=1}^{K} \lambda_{k} y_{m, k} \geq y_{m, o} \\
\sum_{k=1}^{K} \lambda_{k} x_{n, k} \leq \theta \cdot x_{n, o} \\
\sum_{k=1}^{K} \lambda_{k}=1 \\
\lambda_{k} \geq 0
\end{gathered}
$$

$\theta$ represents the technical efficiency which is the percentage of radial reduction to which each of the inputs can potentially be subjected. $\lambda_{k}$ is a vector of $k$ constants representing the weight of each farm in determining the technical efficiency of the specific reference farm $\left(\mathrm{farm}_{0}\right) . x_{n 0}$ and $y_{m 0}$ are respectively the input and the output vectors of the farm ${ }_{0}$. The convexity constraint specifying the VRS assumption is given by the constraint

$$
\sum_{k=1}^{K} \lambda_{k}=1
$$

An individual GWUE score for each farm can be arrived at using the concept of "sub-vector efficiency" [15-19] defined in the following program:

$$
\begin{gathered}
\operatorname{Min}_{\theta^{t}, \lambda} \theta^{t} \\
\text { s.t. } \sum_{k=1}^{K} \lambda_{k} y_{m, k} \geq y_{m, o} \\
\sum_{k=1}^{K} \lambda_{k} x_{n-t, k} \leq x_{n, o} \\
\sum_{k=1}^{K} \lambda_{k} x_{t, k} \leq \theta^{t} \cdot x_{t, o} \\
\sum_{k=1}^{K} \lambda_{k}=1 \\
\lambda_{k} \geq 0
\end{gathered}
$$


The variables are defined as in the previous program model, $\theta^{t}$ in which is the sub-vector efficiency of the input (groundwater) concerned and $x_{t 0}$ is the input concerned from the input vector $x_{n 0}$.

\subsection{Estimating the causal effect}

Understanding and accurately estimating the causal effect of water scarcity $(X)$ on GWUE $(Y)$ is very important to optimize the groundwater use. To understand and estimate the causality, as a first step we use the causal graph to explore the causal link between water scarcity and GWUE and then the estimation is done using a double robust Inverse Probability Weighted (IPW) regression estimate [20].

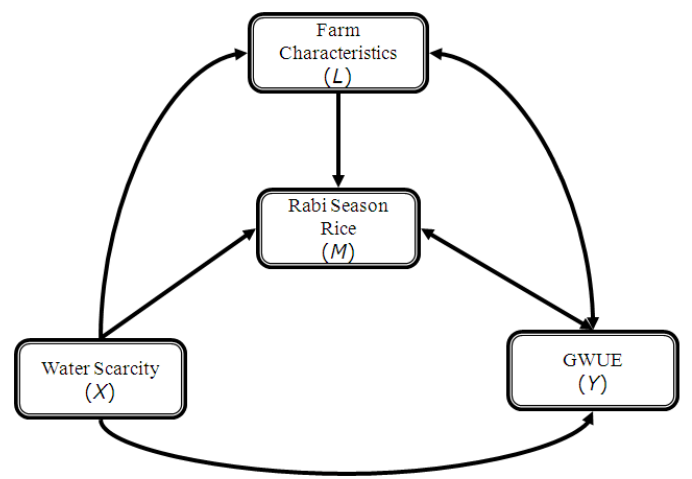

Figure 1: Causal diagram showing the relation between GWUE and water availability.

\subsubsection{The model}

The association between $X$ and $Y$ can be causal (e.g. $X-M-Y$ ) or non-causal (e.g. $X-M-L-Y$ ). The causal graph (Figure 1) represents these relationships. Mainly two approaches are used in this context to estimate the causal relationships: G-estimation and IPW estimates. Since $M$ is a binary response variable, the IPW estimates are preferred in our study [20].

Let $Y_{(x, m)}$ denote the counterfactual outcome, that is the GWUE that would be observed for a given farm if, the water availability $(X)$ is set to $x$ and the choice of Rabi rice $(M)$ to $m$. Here our goal is to measure [20]:

$$
E\left\{Y_{(x, m)}-Y_{(0, m)}\right\}
$$

which is the 'controlled direct effect' as the mediator $(M)$ is controlled at the same level for every farm. This expresses the average change in GWUE when the water availability is increased with $x$ units keeping the choice of rabi rice at a specific level $m$. Robins et al. [21] proposed to model controlled direct effects via the following additive direct model using a marginal structural model (MSM) framework:

$$
E\left[Y_{(x, m)}\right]=\varphi_{0}+\varphi_{x} x+\varphi_{x m} x m
$$


This MSM can be simplified by assuming no interaction between $X$ and $M$ $\left(\varphi_{x m}=0\right)$. Further the above counterfactual model can be used to estimate the controlled direct effects as follows:

$$
E\left\{Y_{(x, m)}-Y_{(0, m)}\right\}=\varphi_{x} x+\varphi_{x m} x m
$$

where $\varphi_{x}$ is the direct exposure effect (which is assumed to be linear and independent of the mediator level i.e., $\left.\varphi_{x m}=0\right)$. More generally, when the above MSM for $E\left[Y_{(x, m)}\right]$ involves any function of $x$ and $z, E\left[Y_{(x, m)}\right]=g(x, m)$, then the controlled direct effect becomes (Van der Weele, 2009):

$$
E\left\{Y_{(x, m)}-Y_{\left(x^{*}, m\right)}\right\}=g(x, m)-g\left(x^{*}, m\right)
$$

When the association between water availability and GWUE is confounded with $C$ and suppose $\varphi_{x m}=0$, this direct exposure effect model (14) can be expressed as

$$
E\left\{Y_{(x, m)}-Y_{(0, m)} \mid C\right\}=\varphi_{x} x+\varphi_{x c} x C
$$

Here the direct effect parameters are $\varphi_{x}$ and $\varphi_{x c}$ where the former tell us the direct exposure effect and the latter encodes the degree to which the direct exposure effect varies depending on $C$ (this can be zero if no interaction between $X$ and $C$ is anticipated). The IPW estimation for the above causal effect can be obtained by the following two step weighting procedure [21, 22]:

$$
\begin{gathered}
w_{i}^{X}=\frac{P\left(X=x_{i}\right)}{P\left(X=x_{i} \mid C=c_{i}\right)} \\
w_{i}^{M}=\frac{P\left(M=m_{i} \mid X=x_{i}\right)}{P\left(M=m_{i} \mid X=x_{i}, C=c_{i}\right)}
\end{gathered}
$$

where, $P\left(X=x_{i} \mid C=c_{i}\right)$ is the probability of the farmer exposed to water scarcity given his farm conditions and other socio economic variables, $P\left(M=m_{i} \mid X=x_{i}, C=c_{i}\right)$ denotes the probability of growing rice during the rabi season conditional on the water scarcity $\left(X=x_{i}\right)$ and covariates $\left(C=c_{i}\right)$ expressing farm conditions and other social situation. If $M$ and $X$ are continuous, the probabilities can be replaced by density functions. Robins et al [21] showed that a weighted regression of $Y$ on $X$ and $M$ in which each individual is weighted with $w_{i}^{X}$ and $w_{i}^{M}$ gives a valid estimate for the marginal structural model (2). We assume that all farms stop with cultivating rice during the rabi season when they have critically low level of water availability.

\subsection{Sample and data}

The sample of 152 rice farms has been chosen by simple random sampling from the villages of Madhugiri. Demographic characteristics of the household, land distribution statistics and the various production-consumption details were collected in a field survey. The survey also covered groundwater pumping details and investment on wells. 


\section{Results and discussion}

\subsection{DEA analysis and GWUE scores}

The individual sub-vector efficiency scores were derived for the total rice production (kharif and rabi) and separately and compared (figure 2).

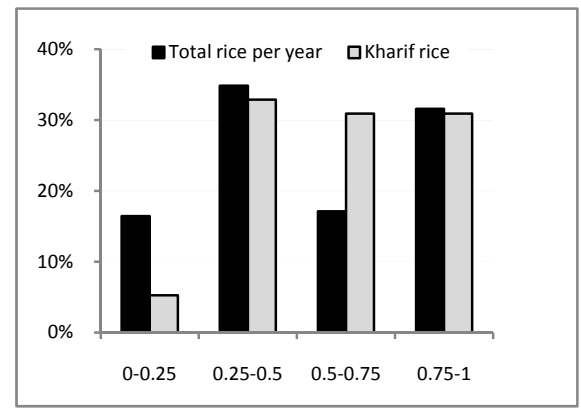

Figure 2: Efficiency scores comparison between kharif and total rice production.

More than 60 percent of the farmers lies in higher efficiency classes when the kharif season is considered separately. However, for the intensive rice production ( 2 crops per year), only 48 percent of the farmers has an efficiency above $50 \%$. The average score of intensive is 0.56 whereas in the case of kharif season the average efficiency score is 0.61 .

\subsection{Marginal structural model for causal effect estimation}

The results (table 1) show a significant negative impact of water scarcity proxy variables on the GWUE $(Y)$ scores. Age of bore-wells $\left(X_{1}\right)$, is a proxy for water scarcity, and it has a negative effect on GWUE. Due to the progressive lowering of the water table, the water scarcity experienced at individual farm level is higher if they possess older wells and this leads to higher inefficiencies. The second proxy, the investment cost in irrigation wells shows a significant positive effect of these investments on GWUE efficiency. This indicates that increasing water availability at farm level increases GWUE. Higher irrigation investments $\left(X_{2}\right)$ at farm level are expected to improve the access to groundwater. This shortterm individual solution to the water scarcity problem is shown to improve GWUE measures at farm level in the current case study. This result together with the impact of the age of bore-well, confirms that decreasing water scarcity at farm level improves groundwater use efficiency levels when other effects are conditioned.

A negative sign for number of bore-wells $\left(X_{3}\right)$ but insignificant coefficient is observed. The combined results of estimation show significant negative impact of water scarcity on the GWUE scores. This seems to indicate the presence of 
appropriative competition and consequent inefficiency of irrigation water use. This result is in line with the experimental studies from the common property resource literature $[10,11,23-25]$. Scarcity induces farms to behave myopically, and often without taking into account the long term consequence of their actions. In this way they ignore dynamic stock externalities. Farm level water scarcity depends on the private well's capacity to yield water, which is often related to the age of the well and investment associated. The presence of rabi season cropping portrayed as a dummy variable in the model affects GWUE scores negatively. This significant negative effect of season on GWUE is an indication that in the kharif season less groundwater is pumped than in the rabi season. This effect is intuitive and we use this to separate the direct causal effect of water scarcity as given by $X_{1}$ and $X_{2}$ from the pure season effect. Results nevertheless show that there is a competitive extraction, leading to inefficient use of groundwater in the dry season even after taking the effect of season out.

Irrigable area $\left(L_{1}\right)$ and farming income $\left(L_{2}\right)$ represent the farm characteristics. The effect of irrigable area on GWUE scores is shown to be marginally significant in the estimation, and the farming income has a significant positive effect on GWUE scores. These coefficients explain the association between the farm income and GWUE through unmeasured confounders.

Table 1: $\quad$ Marginal structural model estimation parameters.

\begin{tabular}{|c|c|c|c|}
\hline & $B$ & S.E & P value \\
\hline Intercept & 6.82 & 3.76 & $<0.001 * * *$ \\
\hline Age of bore-well $(X 1)$ & -8.08 & 3.60 & $0.012^{* *}$ \\
\hline Cost of bore-well $(X 2)$ & 5.66 & 3.23 & $0.039 * *$ \\
\hline Number of bore-wells $(X 3)$ & -5.18 & 5.33 & 0.166 \\
\hline Season of Rice Crop $(M)$ & -3.07 & 4.77 & $<0.001 * * *$ \\
\hline Irrigable area $(L 1)$ & 2.73 & 1.84 & $0.069 *$ \\
\hline Farming Income $(L 2)$ & 4.99 & 7.70 & $<0.001 * * *$ \\
\hline
\end{tabular}

\section{Conclusion}

Groundwater is a fluid CPR for which exclusion and restriction is very difficult in the absence of strong monitoring systems and individual farm use of groundwater depends on specific scarcity conditions and farm characteristics. 
This paper provides a micro level estimation of the nexus between farm level water scarcity and GWUE using the theory of causal inference. We find that farm level water scarcity induces low GWUE scores pointing to the occurrence of appropriative competition for the extraction of groundwater as CPR. Our model reveals that farm level water scarcity indeed affects the GWUE negatively when conditioned on other confounders. This result is similar to the conclusions made in many of the experimental economics literature, where it has been observed that scarcity induces over-extraction. Our approach adds a field based view of this nexus by showing causal association between scarcity and GWUE. For a policy maker, this result translates into three possible options: 1) Supply augmentation at field level from alternative water supply sources; 2) Demand management options: such as crop shifts and technology adoption to reduce irrigation water demand to keep depletion on par with annual groundwater recharge and 3) Improving water institutions and governance by devising mechanisms to regulate pumping, including a legal framework to control inefficient pumping.

\section{References}

[1] Rogers, P., R. De Silva, and R. Bhatia, Water is an economic good: How to use prices to promote equity, efficiency, and sustainability. Water Policy, 2002. 4: p. 1-12.

[2] Molden, D., et al., Improving agricultural water productivity: Between optimism and caution. Agricultural Water Management, 2010. 97(4): p. 528-535.

[3] Molle, F., P. Wester, and P. Hirsch, River basin closure: Processes, implications and responses. Agricultural Water Management, 2010. 97(4): p. 569-577.

[4] Ostrom, E., R. Gardner, and J.M. Walker, Rules, Games and Common-Pool Resources. 1994, Michigan: Ann Arbor, The University of Michigan Press.

[5] Osés-Eraso, N. and M. Viladrich-Grau, On the sustainability of common property resources. Journal of Environmental Economics and Management, 2007. 53(3): p. 393-410.

[6] Leite, C. and J. Weidemann, Does Mother Nature Corrupt? Natural Resources, Corruption and Economic growth., in Working paper of the International Monetary fund. 1999.

[7] Arnold, J.E.M., Managing Forests as Common Property, in Forestry Paper 136, FAO. 1998: Rome.

[8] Ostrom, E., et al., Revisiting the Commons: Local Lessons, Global Challenges. Science, 1999. 284(5412): p. 278-282.

[9] Grossman, H.I. and J. Mendoza, Scarcity and appropriative competition. European Journal of Political Economy, 2003. 19(4): p. 747-758.

[10] Herr, A., R. Gardner, and J.M. Walker, An Experimental Study of TimeIndependent and Time-Dependent Externalities in the Commons. Games and Economic Behavior, 1997. 19(1): p. 77-96. 
[11] Maldonado, J.H. and R.d.P. Moreno-Sanchez, Does scarcity exacerbate the tragedy of the commons? Evidence from fishers' experimental responses. 2008, American Agricultural Economics Association (New Name 2008: Agricultural and Applied Economics Association).

[12] Wadud, A. and B. White, Farm household efficiency in Bangladesh: a comparison of stochastic frontier and DEA methods. Applied Economics, 2000. 32(13): p. 1665 - 1673.

[13] Malano, H., M. Burton, and I. Makin, Benchmarking performance in the irrigation and drainage sector: a tool for change. Irrigation and Drainage, 2004. 53(2): p. 119-133.

[14] Coelli, T.J., et al., An Introduction to Efficiency and Productivity Analysis. Second Edition ed. 2005, Newyork: Springer Science +Business Media.

[15] Frija, A., et al., Water use and technical efficiencies in horticultural greenhouses in Tunisia. Agricultural Water Management, 2009. 96(11): p. 1509-1516.

[16] Speelman, S., et al., A measure for the efficiency of water use and its determinants, a case study of small-scale irrigation schemes in North-West Province, South Africa. Agricultural Systems, 2008. 98(1): p. 31-39.

[17] Lilienfeld, A. and M. Asmild, Estimation of excess water use in irrigated agriculture: A Data Envelopment Analysis approach. Agricultural Water Management, 2007. 94(1-3): p. 73-82.

[18] Lansink, A.O. and E. Silva, Non-Parametric Production Analysis of Pesticides Use in the Netherlands. Journal of Productivity Analysis, 2004. 21(1): p. 49-65.

[19] Färe, R., S. Grosskopf, and C.A.K. Lovell, Production Frontiers. 1994, Cambridge: Cambridge University Press.

[20] Van Steelandt, S., Estimating direct effects in cohort and case-control studies. Epidemiology, 2009. 20: p. 851-860.

[21] Robins, J.M., M.A. Hernán, and B. Brumback, Marginal structural models and causal inference in epidemiology. Epidemiology, 2000. 11: p. 550-560.

[22] Van der Weele, T.J., Marginal structural models for the estimation of direct and indirect effects. Epidemiology, 2009. 20: p. 18-26.

[23] Giordana, G.A., M. Montginoul, and M. Willinger, Do Static Externalities Offset Dynamic Externalities? An Experimental Study of the Exploitation of Substitutable Common-Pool Resources. Agricultural and Resource Economics Review, 2010. 39(2).

[24] Moxnes, E., Not Only the Tragedy of the Commons: Misperceptions of Bioeconomics. Management Science, 1998. 44(9): p. 1234-1248.

[25] Moxnes, E., Overexploitation of renewable resources: The role of misperceptions. Journal of Economic Behavior \& Organization, 1998. 37(1): p. 107-127. 